\title{
Hospital Cost Structure and the Implications on Cost Management During COVID-19
}

J Gen Intern Med 35(9):2807-9

DOI: $10.1007 / \mathrm{s} 11606-020-05996-8$

(C) Society of General Internal Medicine 2020

\section{INTRODUCTION}

The ongoing COVID-19 pandemic has been disrupting hospital operations in the USA. ${ }^{1}$ Thirty states and the District of Columbia issued executive orders requiring that elective procedures be canceled or postponed in order to prioritize hospital capacity, preserve personal protective equipment for COVID-19 care, and ensure the safety of patients and medical staff. ${ }^{2}$ Concerned about potential exposure to infection, patients also have been limiting hospital visits. Facing a sharp decline in revenue, many hospitals have initiated layoffs, furloughs, and salary cuts to contain costs and maintain financial viability. ${ }^{3}$ A detailed analysis of hospital cost structure remains an unexplored area in the literature. This study aims to examine the structure of hospital operating costs and how it varies across cost functions and types in order to understand hospitals' cost management responses during the pandemic.

\section{METHODS}

Using the hospital Cost Reports published by the Centers for Medicare and Medicaid Services, we obtained the cost information for 3521 private general acute care hospitals in 2018,

Received May 25, 2020

Revised May 25, 2020

Accepted June 15, 2020

Published online June 30, 2020 the most recent year for which a complete national dataset is available. We deleted 20 hospitals that reported missing net patient revenue. The sample has 3501 hospitals: 2601 nonprofits and 900 for-profits.

Cost Reports classify hospital operating costs into four categories based on function: overhead costs (not directly associated with patient care), ancillary costs, inpatient costs, and outpatient costs. The amount of the labor component and the non-labor-non-capital component was reported for each cost item within these categories. The capital costs of building and equipment, such as depreciation, were reported in the overhead category. ${ }^{4}$

First, we aggregated the operating costs of all hospitals in the sample. Second, we separated capital costs from other overhead costs, grouped all operating costs based on their type and function, and compared the relative magnitude across groupings. Third, we analyzed the proportion of capital, labor, and non-capital-non-labor components in each major cost item that accounted for at least $0.5 \%$ of total operating costs. Lastly, we identified patient care services (i.e., ancillary, inpatient, and outpatient) that incurred relatively large costs $(>2.0 \%$ of total operating costs) and examined their weight in the cost structure.

\section{RESULTS}

Private short-term general hospitals incurred $\$ 732.2$ billion in total operating costs in 2018. Capital costs and overhead costs accounted for almost half (48.0\%); ancillary, inpatient, and outpatient care accounted for the remaining $52.0 \%$ (Fig. 1). Based on the cost type, noncapital-non-labor costs constituted $54.6 \%$ of total 


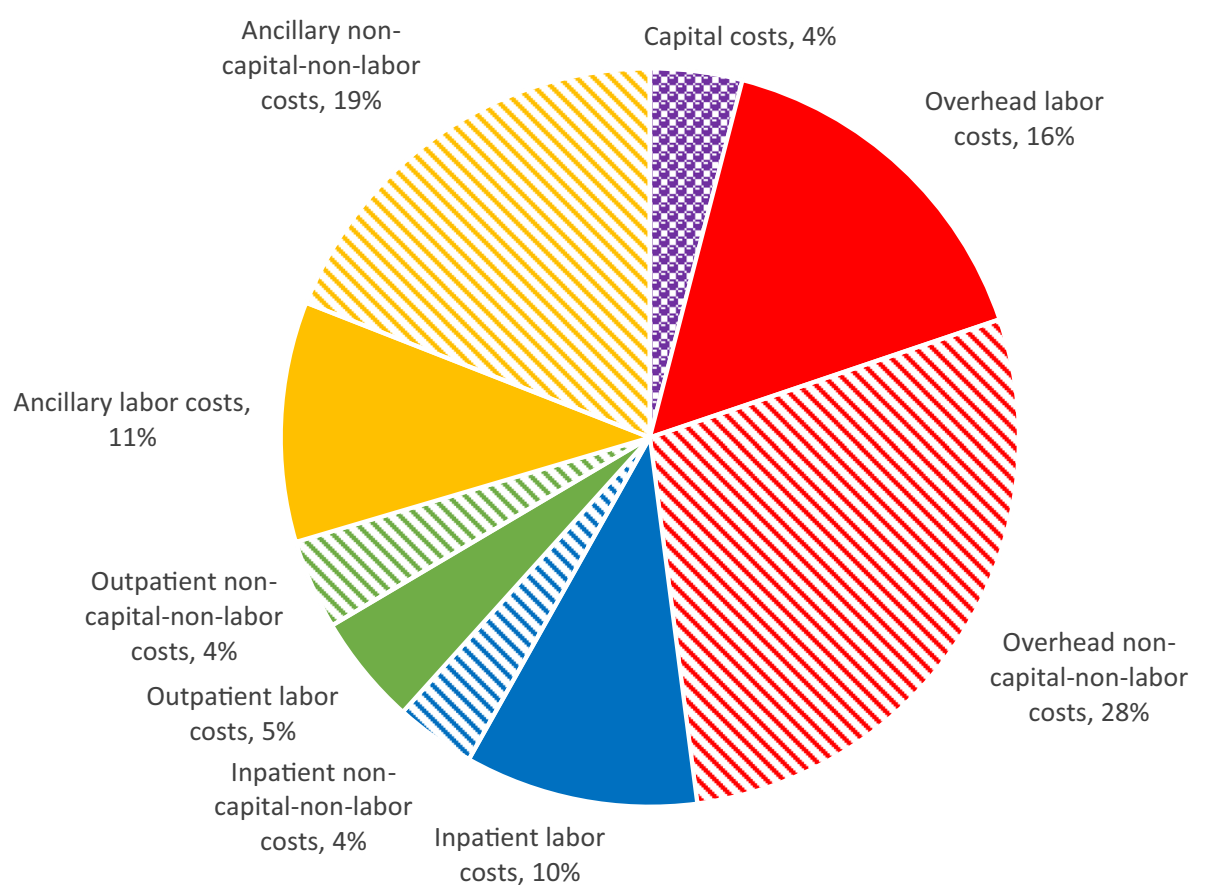

Figure 1 Decomposition of hospital cost, by cost function and type, 2018. Notes: Capital costs include depreciation, lease, rental, interest, taxes, insurances, license, and royalty expenses for land, facilitates, fixtures, and moveable equipment. In Cost Reports, capital costs are included in overhead costs. In this study, we separately report capital costs due to its unique nature.

operating costs $(28.1 \%$ for overhead and $26.5 \%$ for patient care), labor costs $41.3 \%$ ( $15.8 \%$ for overhead and $25.5 \%$ for patient care), and capital costs $4.0 \%$.

Table 1 presents the decomposition of each major cost item. The single largest item is administrative and general costs $\left(21.4 \%\right.$ of all operating costs). ${ }^{5}$ The costs of eight patient care services-operating room (8.4\%), laboratory $(3.8 \%)$, diagnostic radiology $(2.7 \%)$, general routine inpatient care $(9.1 \%)$, intensive care unit $(2.2 \%)$, outpatient clinic (4.2\%), emergency room (3.9\%), and drugs charged to patients $(2.3 \%)$-were greater than $2.0 \%$ of total operating costs. Since the cost for drugs charged to patients contains primarily the inventory cost of drugs, we excluded it from the analysis. The aggregated costs of the seven other patient care services accounted for $34.3 \%$ of all operating costs or $65.9 \%$ of patient care costs.

\section{DISCUSSION}

In 2018, labor and capital costs constituted $41.3 \%$ and $4.0 \%$ of hospital operating costs, respectively. Operating room, laboratory, diagnostic radiology, general routine inpatient care, intensive care unit, outpatient clinic, and emergency room incurred approximately one-third of hospitals' total operating costs. The cancelation of elective surgery and the decline of hospital visits caused by COVID-19 have shrunk revenue from these services and motivated hospitals to reduce costs from these services. When the reduction of non-capital-non-labor costs (e.g., medical supplies) was insufficient, many hospitals chose to cut the labor costs of these services, thus disrupting the compensation of the patient care labor force. Administrative and general costs, constituting more than one-fifth of the operating costs, could provide alternative opportunities for cost management efforts.

The limitation of this study is that the costs were aggregated across all hospitals, and thus the analytical results are sensitive to the cost structure of large hospitals. The patient care labor costs were underestimated, since all employee benefits were included in overhead costs.

Ge Bai, Ph.D, CPA ${ }^{1,2}$

Hossein Zare, $P h D^{2,3}$

${ }^{1}$ Johns Hopkins Carey Business School, Baltimore, Maryland, United States

${ }^{2}$ Department of Health Policy and Management, Johns Hopkins Bloomberg School of Public Health, Baltimore, Maryland, United States ${ }^{3}$ University of Maryland Global Campus, Baltimore, Maryland, USA 
Table 1 Decomposition of Hospital Cost, by Cost Item and Type, 2018

\begin{tabular}{|c|c|c|c|c|}
\hline & Capital (\%) & Labor (\%) & Non-capital-non-labor (\%) & Total (\%) \\
\hline Capital related costs-buildings and fixtures & 2.6 & & & 2.6 \\
\hline Capital related costs-movable equipment & 1.3 & & & 1.3 \\
\hline Other capital related costs & 0.1 & & & 0.1 \\
\hline Total capital costs & 4.0 & & & 4.0 \\
\hline Administrative and general & & 4.0 & 17.3 & 21.4 \\
\hline Employee benefits* & & 5.9 & 0.0 & 5.9 \\
\hline Pharmacy & & 0.9 & 3.8 & 4.8 \\
\hline Operation of plant & & 0.4 & 1.9 & 2.3 \\
\hline Nursing administration & & 1.0 & 0.3 & 1.3 \\
\hline Housekeeping & & 0.6 & 0.6 & 1.2 \\
\hline Dietary & & 0.5 & 0.8 & 1.3 \\
\hline Central services and supply & & 0.3 & 0.8 & 1.1 \\
\hline Maintenance and repairs & & 0.2 & 0.7 & 0.9 \\
\hline Intern \& research service salary \& fringes & & 0.5 & 0.2 & 0.7 \\
\hline Intern \& research other program costs & & 0.2 & 0.5 & 0.7 \\
\hline Medical records \& medical records Library & & 0.3 & 0.3 & 0.6 \\
\hline Other overhead costs $\uparrow$ & & 0.9 & 0.9 & 1.7 \\
\hline Total overhead costs & & 15.8 & 28.1 & 44.0 \\
\hline Operating room & & 2.4 & 6.0 & 8.4 \\
\hline Laboratory & & 1.3 & 2.5 & 3.8 \\
\hline Diagnostic radiology & & 1.4 & 1.3 & 2.7 \\
\hline Drugs charged to patients & & 0.3 & 2.1 & 2.3 \\
\hline Cardiac catheterization & & 0.4 & 1.2 & 1.6 \\
\hline Physical therapy & & 0.8 & 0.3 & 1.1 \\
\hline Respiratory therapy & & 0.7 & 0.3 & 1.1 \\
\hline Labor room and delivery room & & 0.6 & 0.3 & 0.9 \\
\hline Electrocardiology & & 0.4 & 0.5 & 0.9 \\
\hline Anesthesiology & & 0.3 & 0.6 & 0.8 \\
\hline Medical supplies charged to patients & & 0.0 & 0.9 & 0.9 \\
\hline Therapeutic radiology & & 0.3 & 0.4 & 0.6 \\
\hline Implantable devices charged to patients & & 0.0 & 1.0 & 1.0 \\
\hline Recovery room & & 0.4 & 0.1 & 0.5 \\
\hline Other ancillary services $t$ & & 1.3 & 1.7 & 3.0 \\
\hline Total ancillary costs & & 10.5 & 19.0 & 29.5 \\
\hline Adults and pediatrics (general routine care) & & 6.8 & 2.3 & 9.1 \\
\hline Intensive care unit & & 1.6 & 0.6 & 2.2 \\
\hline Other special care & & 0.4 & 0.2 & 0.6 \\
\hline Other inpatient services $\dagger$ & & 1.3 & 0.5 & 1.8 \\
\hline Total inpatient costs & & 10.2 & 3.5 & 13.7 \\
\hline Clinic & & 2.3 & 1.9 & 4.2 \\
\hline Emergency room & & 2.2 & 1.7 & 3.9 \\
\hline Other outpatient services $\dagger$ & & 0.4 & 0.3 & 0.7 \\
\hline Total outpatient costs & & 4.8 & 3.9 & 8.8 \\
\hline Total & 4.0 & 41.3 & 54.9 & 100.0 \\
\hline
\end{tabular}

* Costs for employee benefits were classified as labor costs

†Patient care cost items that incurred greater than $2.0 \%$ of total operating costs, except for "Drugs charged to patients," were indicated in italics. All other cost items $(<0.5 \%$ of total operating costs) and unspecified items were aggregated and presented as other services for each cost category

Corresponding Author: Ge Bai, Ph.D, CPA; Johns Hopkins Carey Business School, Baltimore, Maryland, United States (e-mail: gbai@jhu.edu).

\section{Compliance with Ethical Standards:}

Conflict of Interest: Ge Bai has served as an expert witness for plaintiffs in lawsuits in which some hospitals were the defendants. Hossein Zare declares no potential conflicts of interest with respect to the research, authorship, or publication of this article. This research is not funded by any organization.

\section{REFERENCES}

1. Chopra V, Toner E, Waldhorn R, Washer L. How should U.S. hospitals prepare for coronavirus disease 2019 (COVID-19)? Ann Intern Med. 2020 doi:https://doi.org/10.7326/M20-0907
2. American College of Surgeons. COVID-19: Executive Orders by State on Dental, Medical, and Surgical Procedures. https://www.facs.org/covid19/legislative-regulatory/executive-orders. Accessed May 22, 2020.

3. Kliff S. Hospitals knew how to make money. Then coronavirus happened. New York Times. https://www.nytimes.com/2020/05/15/us/hospitalsrevenue-coronavirus.html. Accessed May 22, 2020.

4. Center for Medicare and Medicaid Services. The provider reimbursement manual - part 2. https://www.cms.gov/Regulations-and-Guidance/Guidance/Manuals/Paper-Based-Manuals-Items/CMS02 1935. Accessed May 22, 2020.

5. Himmelstein DU, Jun M, Busse R, Chevreul K, Geissler A, Jeuissen P, Thomason S, Vinet M, Woolhandler S. A comparison of hospital administrative costs in eight nations: US costs exceed all others by far. Heath Aff (Millwood). 2014;33:1586-94. https://doi.org/10.1377/hlthaff.2013. 1327. This is a conservative estimation as compared with a previous study on hospital administrative costs, mainly because capital costs were excluded from overhead costs and separately examined in this study.

Publisher's Note: Springer Nature remains neutral with regard to jurisdictional claims in published maps and institutional affiliations. 